drawn from a series of measurements by a relatively non-specific technique.

Serum vitamin $\mathrm{A}$ has been measured by a variety of colorimetric methods (for example, those of Bessey et al..$^{1}$ and of Neeld and Pearson ${ }^{2}$ ) which consistently give a mean adult concentration of about $32 \mu \mathrm{g} / 100 \mathrm{ml}$ (range 21-47 $\mu \mathrm{g} / 100 \mathrm{ml}$ ). ${ }^{3}$ All are inaccurate when serum carotenoid levels are high. More recently, fluorimetric methods have been employed in an attempt to overcome this problem. Hansen and Warwick used a modification of Kahan's ${ }^{3}$ extraction procedure to obtain a mean adult serum vitamin A level of $133 \mu \mathrm{g} / 100 \mathrm{ml}$. After Thompson et al. ${ }^{6}$ had reported that phytofluene interferes with the fluorimetric estimation of serum vitamin A Garry et al. ${ }^{7}$ devised a method for separating the two compounds before measuring the fluorescence of the plasma extract. With this technique they reported that the mean serum vitamin $A$ is reduced to a value of $34 \mu \mathrm{g} / 100 \mathrm{ml}$, and my colleagues and $I$, at the Institute of Child Health, Birmingham, have ubtained values of the same order of magnitude (mean \pm S.D. $=$ $39 \pm 15 \mu \mathrm{g} / 100 \mathrm{ml}){ }^{8}$

Recently a method was developed for measuring levels of both vitamin $A$ and phytofluene in the same $200-\mu 1$ serum sample ${ }^{9}$ and these compounds were measured in serum from healthy individuals. No correlation was detected between the two sets of values. Phytofluene was present in all samples at a substantial though variable level.

The point I wish to make is that Mrs. Wild and her colleagues have used the method of Hansen and Warwick, which is inaccurate, for estimating vitamin A levels in the presence of phytofluene. In view of the findings of Bubb and Murphy their assumption that phytofluene is responsible for a small and constant contribution to this measurement is clearly inadmissible. Thus they have failed to prove that any of the serum vitamin A measurements in their subjects fell outside the normal adult range. In consequence their contention that a maternal serum vitamin A level of $94 \mu \mathrm{g} / 100$ $\mathrm{ml}$ or more does not present a teratogenic hazard to the fetus remains unproved.-I am, etc.,

FIona A. BubB

Bernhard Baron Memorial Research Laboratories, Queen Charlotte's Maternity Hospital,

London $\mathbf{W . 6}$

1 Bessey, O. A., Lowry, O. H., Brock, M. J., and Lopez, J. A.,

2 Neeld, J. B., and Pearson, W. N., Fournal of Nutrition, 1963, 79, 454.

3 Annison, E. F., Biochemical foumal, 1954, 58, 670 .

Hansen, L. G., and Warwick, w. J., American Fournal of Clinical Pathology, 1969, S1, 538 . Kahan, J. A., Scandinavian fourmal of Clinical

6 Thompson, J. N., Erdody, P., Brien, R., and 29, 564 .

Garry, P. J., Pollack, J. D., and Owen, G. M., Clinical Chemistry, 1970, 16, 766

Bubb, F. A. (1973) M.Sc. Thesis, University of

Bubb, F. A., and Murphy, G. M., Clinica Chimica Acta, 1973, 48, 329.

\section{I-Fibrinogen and Blocking of the} Thyroid Gland

SIR,-In almost all papers concerning the diagnosis of venous thrombosis with ${ }^{125}$ I-fibrinogen the blocking of the thyroid gland by $100 \mathrm{mg}$ of sodium iodide or $150 \mathrm{mg}$ of potassium iodide is described. The iodide is given orally 24 hours before injection of ${ }^{125 I-f i b r i n o g e n}$ and the dose repeated daily for three weeks.

Radioiodine studies of thyroid blocking and recovery ${ }^{1}$ have shown that the time taken to achieve the blocked state would appear to be about half an hour after giving $100 \mathrm{mg}$ of iodine orally. At that dose the recovery from the blocked state to $1 \%$ of normal uptake is 24 hours and to $100 \%$ of normal uptake eight days. The 24-hour blocking time is a disadvantage in the ${ }^{125}$ I-fibrinogen method. With no blocking time the investigation can start immediately.

Because of the relatively low fraction of free iodine in the labelled fibrinogen the amount of radioiodine taken up in the thyroid during the first two hours can be neglected. Thus if iodide is given orally together with the ${ }^{125}$ I-fibrinogen, in practice the thyroid will be blocked as effectively as if iodide were given before injection of the ${ }^{125}$ I-fibrinogen. As a suitable blocking dose I initially give $400 \mathrm{mg}$ of potassium iodide orally and follow it with $200 \mathrm{mg}$ daily for the next three weeks.-I am, etc.,

Department of Haematology,

KRISTER FORSBERG

Sarolinska Sjukhuset,

Storing

Ramsden, D., Passant, F. H., Peabody, C. O., and

Anticonvulsant Osteomalacia and Vitamin D

SIR,-Dr. Claus Christiansen and his colleagues (22 December, p. 695), using photon absorptiometry, have demonstrated in their careful paper a decreased bone mineral content (B.M.C.) in the forearm bones of epileptic subjects compared with a normal control population. B.M.C. was lowest in those epileptics with hypocalcaemia and/or increased plasma alkaline phosphatase. The authors also demonstrated a significant increase in B.M.C. in epileptics when they were treated with 2,000 IU of vitamin $\mathrm{D}_{3}$ daily. While we accept that photon absonptiometry may offer a new and sensitive method for studying abnormalities of bone mineralization, we feel we should attempt to qualify the enthusiasm with which the authors diagnose the presence of "anticonvulsant osteomalacia." They consider that the presence of any of the followingincreased serum alkaline phosphatase, decreased serum calcium, and decreased B.M.C.-indicates the presence of "anticonvulsant osteomalacia."

One of us has previously demonstrated, using polyacrylamide gel electrophoresis, that the significant increase in plasma total alkaline phosphatase levels in adult epileptics is due to an increase in the hepatic isoenzyme. ${ }^{12}$ Mean levels of alkaline phosphatase of bone origin were no higher in adult epileptics than in normal adults. Also mean urinary levels of total hydroxyproline were no longer higher in adult epileptics than in normal adults $(33.1$ and $35.8 \mathrm{mg}$ per 24 hours respectively). In this situation determination of plasma total alkaline phosphatase is of limited value in the diagnosis of osteomalacia.

Hypocalcaemia is common in epileptic subjects without other biochemical indications of osteomalacia and has been found in the absence of histological abnormalities in bone. $^{3}$ The lack of increase in serum calcium levels in epilep:ic subjects which these authors found after treatment with 2,000 IU of vitamin $D_{3}$ daily is in agreement with other studies; epileptic subjects with marginal hypocalcaernia were treated with even larger doses, either 10,000 or 50,000 IU vitamin D daily for seven months without effect upon plasma calcium levels." The presence of hypocalcaemia without other biochemical abnormality in epileptic subjects may therefore not always indicate osteomalacia but may instead reflect a second anticonvulsant effect upon calcium metabolism, as has been suggested by others. ${ }^{5}$ An association between epilepsy and osteoporosis has been, recognized for some time ${ }^{6}$ and in our experience is appreciably more common than a finding of osteomalacia. A lowered B.M.C. has not been reported to distinguish between these forms of skeletal rarefaction.

Whatever the reason for diminished B.M.C. the effects of treatment with small doses of vitamin D on B.M.C. are at variance with the results of calcium balance studies, and better understanding of the relation between these measurements is clearly necessary. From their data the authors calculate that the change in B.M.C. is equivalent to a positive calcium balance of $300 \mathrm{mg}$ daily. Such changes do not occur during the treatment of osteoporosis of any origin since the disease does not satisfactorily respond to treatment. ${ }^{6}$ While large positive balances certainly result from the treatment of osteomalacia with adequate vitamin D, "anticonvulsant osteomalacia" typically shows great resistance to the low doses (2,000 IU daily) which were used by these authors. ${ }^{7-9}$ We should therefore like to emphasize that the question of prophylactic vitamin $D$ in the region of 2,000 IU daily merely a cost-benefit exercise, since doses of vitamin $\mathrm{D}$ in the region of 2,000 IU daily may prove insufficient either to heal anticonvulsant rickets or even to prevent its occurrence. ${ }^{9}$ We support the final conclusion of these authors concerning the necessity for close clinical supervision of all epileptic patients.-We are, etc.,

David J. F. Rowe T. C. B. STAMP

University College Hospital Medical School,

London $W . C .1$

1 Richens, A., and Rowe, D. J. F., British Medical fournal, 1970, 4, 73.

Rowe, D. J. F., Ph.D. Thesis, University of London, 1973.

3 Dent, C. E., Rowe, D. J. F., and Stamp, T. C. B.,

unpublished data. Rowe, D. J. F., unpublished
Richens, A., and Ro data. Clinical Science and Molecular Medicine, 1973,
45,

Dent, C. C. E., and Watson, L., Postgraduate Medical Yournal, 1966; 42, Oct. (Suppl.) p. 581. Stamp, T.'C. B., British Medical Fournal, 1970, 4,69 . 8 Stamp, T. C. B., Round, J. M., Rowe, D. J. F.,

1297, 67, 6.t.
Stamp, T. C. B., Proceedings of the Royal Society of Medicine, 1974, 67, 64.

\section{Pyomyositis in London}

SIR,-Colonel D. D. O'Brien (12 January, p. 78) is right in saying that many pyomyositis patients have a solitary muscle abscess, but in my letter (27 October, p. 235) I made no claim to the contrary. Having stated that pyomyositis was the formation of abscesses 